\title{
Poverty amongst Female-headed Households in Bosnia and Herzegovina : an empirical analysis
}

\section{Senada Smajic and Sergio Ermacora}

\section{Abstract}

This paper conducts an empirical investigation of whether female-headed households (FHHs) are over-represented amongst the poor compared to male-headed households in Bosnia and Herzegovina (BiH), measured through the consumption dimension of poverty. Apart from self-reported and demographic definitions of headship, which do not make reference to the economic support provided for a household, households whose headship is assigned according to economic definition are included in the analysis. Moreover, the heterogeneity of FHHs is recognised in our study. In this way, the study avoids the main pitfalls associated with similar studies. Since the relationship between poverty and headship has regional and ethnic characteristics, the specific characteristics of BiH in this context are taken into account. Finally, given that our analysis did not find evidence of FHHs being disadvantaged in terms of household consumption, it cannot be argued that policy measures targeting FHHs would be a useful approach to reducing poverty in Bosnia and Herzegovina.

JEL: 13, J7, R2

DOI: $10.2478 / \mathrm{v} 10033-007-0017-x$

\section{Introduction}

The notion of the 'feminization of poverty' has become orthodoxy in the last decade. The feminization of poverty has been used as a rationale for advocating public and private-sector policies that target female-headed households in order to assist them in tackling poverty. There are a number of reasons, such as gender inequalities in terms of rights, earnings, economic opportunities, education and capabilities (Chant 1997), the greater longevity of women, the burden of home responsibilities, gender-differentiated effects of transition, and the growth of female-headed households, that are considered responsible for the higher incidence of poverty amongst women than men. The levels of female- headed households in Bosnia and Herzegovina receiving welfare have also been affected by a civil war that caused extensive destruction, atrocities, social and labour market disruption for many adult males, and a decline in the overall standard of living.

In our analysis of the consumption dimension of poverty, data collected in the Living Standard Measurement Survey 2001 (LSMS) for Bosnia and Herzegovina have been employed to examine whether female-headed households are over-represented amongst the poor compared to male-headed households. This enables us to consider whether additional policies targeted at female-headed households would be justified in the case of Bosnia and Herzegovina.

In analysing the incidence of poverty in female-headed households, one of the major issues is the definition of "headship." Because there is no common agreement on this

definition, several criteria for headship are adopted in this study. Rather than using self-reported and demographic definitions of households which do not make reference to the source of economic support, this analysis only used households whose headship was assigned on a strictly economic basis. In this way, the problem associated with households in which, because of social norms, preference is given to men when declaring

*Smajic: , LSE Consortium Sarajevo,

Ermacora, Independent researcher,

A.B. Simica 5, 71000 Sarajevo, Bosnia and Herzegovina 
headship- even when the woman is the main contributor to the household's income- is circumvented. Moreover, because empirical evidence suggests that some groups are more vulnerable to poverty than others this analysis takes into account the heterogeneity of female-headed households. Since the relationship between poverty and headship has regional and ethnic characteristics, characteristics specific to Bosnia and Herzegovina in this context are taken into account. Namely, the examination of poverty amongst female-headed households is done separately for the whole country, each entity, and three types of municipalities, defined according to their level of urbanisation.

Furthermore, our assumption is that wages earned in the labour market typically dominate household income and, in their absence, household income and consumption primarily depend on social benefits provided by the state. For this reason, an investigation of the labour force participation of women and female heads-of- household, as well as a critical analysis of the social benefits system, is conducted to contribute to a fuller picture of the consumption dimension of poverty amongst FHHs.

The study is organised as follows: section 2 surveys the theoretical foundations and empirical findings with respect to the poverty of female- headed households, as well as the issues related to the definition of headship and the methodology applied in our analysis of poverty of female-headed households. Section 3 describes the context of Bosnia and Herzegovina, the data used in the analyses, and examines to what extent different categories of female-headed households are represented in the dataset used. Additionally, it provides an insight into levels of participation in the labour market in terms of gender and headship composition, as well as an empirical investigation of the determinants of women's decision to join the labour market. Given that, in addition to wages earned in the labour market, social benefits represent a significant source of finances for some households, an overview of social policies in Bosnia and Herzegovina is provided in the remainder of section 3. In addition to a survey of female- and male-headed households that fall below the general poverty line, an empirical analysis is undertaken to examine and compare the yearly per capita consumption of these households in section 4. Finally, policy implications arising from this study, concluding remarks and recommendations for further research are presented in the last section.

\section{Literature Survey of Poverty amongst Female- Headed Households}

\subsection{Theoretical Framework}

The term 'feminization of poverty' suggests that women are disproportionately represented amongst the poor compared to men due to the growth of female-headed households ( $\mathrm{FHHs}$ ), gender inequality, disadvantages in terms of entitlements such as restricted access to land ownership, credit and other productive resources, and limited capabilities from illiteracy and low educational levels. Furthermore, the neo-liberal restructuring of market sectors, including the transition of socialist countries, increasing family break-up, the growing involvement of women in the informal economy, and lack of kin-related support as a result of migration, conflicts and similar events negatively affected the well-being of women (Chant 1997; Moghadam 2005; BRIDGE 2001). The main reason why women tend to be more vulnerable to poverty than men is their inferior access to employment and a lower earning capacity possibly caused by occupational segregation, gender earnings differentials and unemployment ${ }^{1}$, a greater tendency to have children, as well the burden of more dependents to support and care for (BRIDGE 1997; Fuwa 1999; ILO 1996; Rosenhouse 1989).

The feminisation of poverty in transitional economies, apart from the above stated subjects, concerns the structural adjustments and market reforms that are believed responsible for the situation in which a greater proportion of transition costs are attached to women than men (Moghadam 2005; Schnepf 2004). Transition in Central and Eastern Europe brought a number of changes that negatively affected the welfare of households in general. Apart from facing job losses, the decline in public sector employment, the growth of a largely unregulated private labour market and the rise in prices, individuals were deprived of a number of subsidies, family benefits, social protection and the centralised system of wage setting provided by the socialist system (Paci 2002). In particular, individuals previously enjoyed free education, health care, fully paid maternity leave and paid leave for the care of a sick child (- 2002). In addition, women in Bosnia and Herzegovina faced the additional

1 There are a number of explanations for gender earnings differentials; the neoclassical approach focuses on differences in human capital as a main factor affecting differences in earnings, allowing for only temporary gender discrimination. Feminist theory underlines "the organization of social reproduction", the respective positions of men and women in the labour marker, and ideological factors (BRIDGE, 1997:27). 
disadvantage of forced family disintegration that arose from a war which left many without the traditionally male breadwinner $^{2}$. Due to the death toll, ethnic cleansing, and damaged family-based social networks, there are large proportions of FHHs in some areas, such as Srebrenica, where approximately 42 percent of all returnees live in FHHs (United Nations Volunteers 2004).

There is an argument in the literature that the labour force participation of women in transition was affected by two factors working in opposite directions (Paci 2002). The first factor is related to higher male unemployment and the weakening of the 'male breadwinner' norm, which is expected to have a positive influence on women's participation in the labour market and to reduce the gender wage gap by reducing occupational segregation and gender discrimination (- 2002). The second factor relies on the argument that women tend to spend a higher proportion of their time in household production and care-giving activities that normally hamper female labour participation (- 2002). In addition, Mickiewicz (2005:87) argues that part of the reason for a decrease in the labour market activity rates lies in the "natural adjustment in activity rate, following the dismantling of the command economy system" and higher incentives to obtain higher education under the 'new' market system. Limited empirical evidence suggests that female participation has declined and that the gender gap in both participation and wages has grown. Milanovic (1998) points out that a larger proportion of women who previously worked as clerical staff, production workers, teachers, administrators and doctors experienced a decrease in terms of employment and wages, giving rise to a greater income gap between women and men, increasing the poverty of the former. In addition, Blackburn et al. (2001) find that occupational segregation in Eastern Europe increased between 1990 and 2000, reaching levels typical of Western Europe and other industrialised countries. This implies that women tend to concentrate around relatively low-paying jobs, which in turn contributes to income inequality and potentially increases their vulnerability to poverty. The latter may have a particularly negative effect on the welfare of some sub-groups of female-headed households, especially in the absence of an effective social benefits system.

In the literature, female-headed households are often linked to the notion of the feminisation of poverty, which sometimes goes as far as to draw a parallel between the two (Jackson 1996; Kabeer 1996). It is widely believed this stems from FHHs comprising a large portion of poor households and the prevalence of $\mathrm{FHH}$ amongst extremely poor ${ }^{3}$ households (BRIDGE 2001; Buvinic and Gupta 1997). Evidence shows that approximately one third of all households in the developing world are headed by women (Buvinic and Youssef 1978 cited by Rosenhouse 1989).

A number of poverty analyses, as presented below, reveal that there is a positive relationship between female-headed households and poverty. This has been a rationale for the argument that creating and implementing policy measures which target this particular sub-group of households is advisable (Buvinic and Gupta 1997 cited in BRIDGE 1995; Fuwa 1999; Joshi 2004).

\section{"Governments that wish to implement anti-poverty programs with constrained budgets should seriously consider targeting female-maintained families ${ }^{4 " .}$ (Buvinic and Gupta (1997) cited in BRIDGE 1995)}

Buvinic (1990) suggests three sets of factors that are likely to determine the prevalence of poverty amongst FHHs. Firstly, female-headed households are poorer because they support more dependants, i.e. have a higher ratio of non-workers to workers compared to other types of households. Secondly, female heads have lower wages, fewer assets, less access to remunerative jobs and productive resources than male-headed ones. The final set of factors, which combines the effects of gender differences and characteristics specific to $\mathrm{FHHs}$, includes time and mobility constraints as well as the burden of household chores that women bear. Rosenhouse (1989), Agarwal (2001), Judith and Dwyer (1988) support the argument of creating policy interventions targeting $\mathrm{FHH}$ due to their specific burdens, including having a single earner, discrimination in the labour market, and time constraints arising from added domestic responsibilities.

Nevertheless, several authors suggest that "headship analysis should not be seen as a proxy for gender analysis of poverty" (Fuwa 1999:4) for the reason that the analysis of poverty in FHHs focuses on the household-level, rather than the individual-level, and that female-headed households do not exclude the men living in these households (Fuwa 1999; Judith and Lloyd 1992; Quisumbing et al. 1995).

\section{Up to 250000 men were killed during the war in Bosnia and Herzegovina. (Kukanesen 2003)} ${ }^{3}$ Extreme economic poverty is defined as living on less
than $\$ 1$ per day (World Bank, undated).

${ }^{4}$ Buvinic and Gupta (1997) distinguish between femaleheaded households as residential units and female-maintained households that consist of kin residing on their own or in larger households. 


\subsection{Definition of Female- Headed Household}

An issue commonly discussed in the literature on $\mathrm{FHH}$ poverty is that of the definition of "headship". A number of definitions are used in national surveys by survey respondents that conflict with definitions based on contributions to household income $^{5}$. (Rosenhouse 1989; Kennedy and Peters 1992; Kennedy and Haddad 1994; Handa 1994) The definition of headship is an important issue in creating effective anti-poverty policies (Rosenhouse 1989).

\section{"If policymakers are concerned with the economic base of poor households, then ideally what is needed is a classification system that identifies whose work effort and income the household is most consistently dependent on."}

(Rosenhouse 1989:7)

Fuwa (1999) gives three broad categories of FHH definitions: self-reported, demographic, and economic. The self-reported household category is often created based on respondents' statements in surveys and censuses, although there is no precise definition. Demographic definitions take account of $\mathrm{FHHs}$ where there is male partner that is temporarily absent, and of FHHs where the female head is separated, divorced, widowed or single (-1999). Further disaggregation of households can be done in terms of de facto and de jure FHHs. De facto FHHs are those households where the self-reported male head is absent the majority of the time (- 1999; Quisumbing et al.1995). De jure female-headed households are those usually headed by widows or unmarried, divorced or separated women. Finally, FHHs may be defined depending on the level of economic contribution of females to the household. Fuwa (1999) suggests defining headship in terms of the largest cash earner in the household. Rogers (1995) advocates a distinction in terms of the 'major earner,' i.e. an earner who contributes 50 percent or more to the household earnings. Gammage (1989) uses the term 'female- maintained' to describe this particular type of household. Moreover, Rosenhouse (1989) uses the 'working head' definition for the household member most heavily engaged in income-generating activities, which includes activities in the labour market as well as family labour (but excludes household chores or child care) in order to emphasise the dual burden attached to female workers.

Self-reported headship measures used in survey data have been criticised by a number of authors (Rosenhouse, 1989; Kennedy and Peters, 1992; Handa, 1994, Quisumbing et al. 2001) who argue that these measures are imprecise, particularly when the oldest male member, despite there being a female main earner, is reported as the household head because of social, religious and cultural norms. This argument may be of particular relevance to the analysis of $\mathrm{FHHs}$ poverty in Bosnia and Herzegovina, especially in rural areas, where the oldest male household member is often considered to be the head. Moreover, it has been pointed out that.

\section{"If the head of the household is only a reference point, without any economic responsibility, there is no immediate reason for the sex of the head to be correlated with the poverty level of the household." \\ Gangopadhyay and Wadhwa (2003:4)}

Unsurprisingly, empirical findings vary when the definition of household head alters, although Buvinic and Gupta (1997) point out that the incidence of poverty may not have the same probability in different countries, even if a common definition of FHHs is used, given country-specific characteristics such as economic and social circumstances.

\subsection{Methodology}

There are several methodological issues that may be the cause of the inconsistent results presented in the literature. Generally, country studies report that the relationship between female headship and poverty differs depending on the disaggregation of reported headship by marital status and other demographic characteristics, as well as on the headship definitions used (Barros et al. 1994; DeGraff and Bilsborrow 1992; Dreze and Srinivasan 1997; Fuwa 1999; Kennedy and Haddad 1994; Louat et al. 1992).

Most analyses of female headship do not account for the heterogeneity within female household heads ${ }^{6}$ (Mukhopadhyay and Ghatak undated; Fuwa 1999; Buvinic and Gupta 1997). As stated above, female-headed households may be created in a number of ways, voluntarily or involuntarily; in particular as a result of conflict, migration, divorce, separation, polygamy, teenage pregnancy and widowhood. Given the different reasons for a household having a female head, it is reasonable to expect that the socio-economic statuses of these households

\footnotetext{
5 In most national and international data sources 'female household headship' refers to situations where an adult woman (usually with children) resides without a male partner (or, in some cases, another adult male such as a father or brother) (Chant, 1997).
}

6 Exceptions are Rosenhouse (1989); Kennedy and Haddad (1994); Handa (1994); Dreze and Srinivasan (1997). 
are not the same. Also, the structure of different types of FHHs is likely to be different across countries and regions (Buvinic and Gupta 1997), suggesting that the relationship between poverty and $\mathrm{FHHs}$ is not straightforward, and that caution is required in modelling poverty-reduction strategies in terms of target groups. As presented in the section below, studies suggest that the relationships between female headship and poverty significantly differ depending on the further disaggregation of reported headship by marital status and other demographic characteristics and/or on alternative headship definitions, such as the economic definition.

They also emphasise the need to use a variety of measures of poverty, such as economic (expenditure and income measures) and non-income measures (Fuwa 1999; Buvinic 1990). In particular, there are several non-income dimensions of poverty, such as housing, access to water and sanitation, basic health care and education that need to be examined in order to obtain a fuller picture of the welfare conditions and potential poverty of FHHs. Additionally, one of the frequently discussed issues is related to both the smaller amount of leisure time of female heads and the intergenerational transmission of the disadvantages of FHHs. Because of the 'double burden' imposed on female heads, i.e. economic support and household chores, there is the argument that female heads are more likely to be 'time poor' compared to other women and male heads (Fuwa 1999). Furthermore, this substitution of work for leisure to achieve a certain level of consumption in female-headed households may signify the perpetuation of poverty into the next generation (Buvinic and Gupta 1997).

Ignoring the endogeneity of households by assuming that female-headed households and other measures of household structure are exogenously determined, i.e. that female headship determines the level of households' welfare and possibly causes poverty, is another methodological issue that may lead to biased results (Foster 1993; Quisumbing et al.1995; Foster and Rosenzweig 2001; Joshi 2004). Namely, female headship and the welfare level of household members may be jointly determined, i.e. there may be some unobserved factor(s) that affects both female headship and the consumption of female-headed households. In order to assess the effects of female headship on the welfare of households, it has been argued that it is necessary to take into account a given woman's characteristics, the socio-economic circumstances of her natal home, the characteristics of its marriage market, as well as the processes that lead to the formation and dissolution of the household and the change in household composition (Alderman et al. 1995, Fuwa 1999). For example, a woman may choose to become either a household head or a wife as a func- tion of her expected income, consumption level or leisure in alternative headship states (Handa 1996 cited by Fuwa 1999). Nevertheless, few studies have adopted an approach with an instrumental variable controlling for potential endogeneity because of the difficulty in finding a valid instrument when analysing cross-section data.

Finally, it is widely argued in the literature that the concepts of adult equivalents and economies of scale in household consumption need to be taken into account when analysing household poverty (Buhmann et al. 1988; Lanjouw et al. 1998; Fuwa 1999; Joshi 2004). This is because children and adults do not consume at the same levels and because economies of scale exist in households due to their different size. Because FHHs are typically small, it is argued that

\section{"...female-headed households appear poorer with greater economies of scale because of the negative correlation} between this household type and average household size".

Lanjouw et al. (1998:7)

\subsection{Empirical Evidence}

It has been suggested that FHHs are much more likely to be poorer than aged or disabled families (Garfinkel and Mclanahan 1986) and are more likely to be poor at any point in time compared to male-headed households (Kossoudji and Mueller 1983). Moreover, Dréze and Srinivasan (1997) found that widow-headed households in India (equivalence-scale adjusted) have lower household per-capita expenditures than other categories of FHHs. A few studies which employed alternative 'economic' headship definition in terms of hours worked and earned income suggest that there is a negative relation between female headship and greater poverty compared to the self-reported headship definition (Rogers 1995; Handa 1994).

Generally, the incidence of poverty amongst FHHs is relatively high in both developed and developing countries. In the United States, for example, the poverty rate of $\mathrm{FHH}$ s was three to four times higher than those of households with two parents in 1983 (Garfinkel and Mclanahan 1986). The review cited often in the literature was conducted by Buvinic and Gupta (1997), which included 61 studies on the relationship between female headship and poverty in Latin America, Africa and Asia. They found that, in two-thirds of cases, FHHs are poorer than MHHs. In contrast, Quisumbing, et al. (1995) conducted an analysis of incidence of poverty amongst FHHs in 10 developing countries ${ }^{7}$, using a number of different poverty measures, and found that the relationship between female headship and 
poverty is strong in only two countries, Ghana and Bangladesh. However, Quisumbing et al. (1995: 25), emphasise that these results "should not be taken to argue that policy interventions should not be targeted by gender", warning that part of the reason why FHHs are not found to be poorer than male-headed households (MHHs) may be related to both methodology and the definition of headship used.

Lanjoulw et al. (1998) examined poverty in different types of households in 7 countries from Eastern European and the former Soviet Union using per capita consumption as a measure of household welfare. They found that female-headed households appear to be relatively poorer when compared with other vulnerable groups, namely the elderly and children, with the incidence of poverty amongst $\mathrm{FHH}$ ranging from 9 percent in Poland to 19 percent in Russia. Moreover, when economies of scale are taken into account, FHHs appear on average to be poorer than the rest of the population, given that these households tend to be associated with lower household size (-1998). Paci (2002) found mixed results with respect to the income dimension of poverty of FHHs in Eastern Europe and the countries of the former Soviet Union. The incidence of poverty for female-headed households in Russia, Kazakhstan and Ukraine is equal to that of male-headed ones. In Albania, Bulgaria, Hungary, Latvia, Moldova, and Romania certain subgroups of $\mathrm{FHHs}$, in particular elderly single women or single mothers, are more likely to have lower income than male counterparts (- 2002). "Only in Georgia and Tajikistan is the gender of the household head per se a correlate of income poverty"( - 2002:xii).

Furthermore, the Poverty Assessment for Bosnia and Herzegovina (World Bank 2003), which used consumption aggregate per capita with adjustment for spatial price variation, has made only a weak reference to FHHs. This analysis suggests that poor households in Bosnia and Herzegovina are predominantly those who have children, are headed by working-age adults, and rely on a single earner. Nevertheless, it found that FHHs in Bosnia and Herzegovina have a lower incidence of poverty than male-headed ones. The finding on the lower poverty amongst $\mathrm{FHHs}$ remains even when the adjustment for economies of scale of consumption is made (- 2003). The Assessment primarily holds responsible the safety net arrangements in Bosnia and Herzegovina for smaller incidence of poverty amongst FHHs. It is not stated, though, which definition of $\mathrm{FHH}$ is used in this analysis, which is, as argued above, one of the main reasons for ambiguous results in different poverty analyses of $\mathrm{FHHs}^{8}$. Also, it seems that the above-mentioned study ignores the heterogeneity of female-headed households, which is considered to be another pitfall of similar studies.

\section{Labour Force Participation of Women in Bosnia and Herzegovina}

\subsection{Data and Bosnian context}

An analysis of the female labour force participation and of the consumption dimension of poverty of FHHs in Bosnia and Herzegovina is conducted using household-level data on the living standards of the population. The LSMS was carried out in 2001 in Bosnia and it collected information from 5,400 households and 17,127 individuals on their income, consumption levels, economic activities, housing etc. The survey sample provides representative data for households in $\mathrm{BiH}$ as a whole, and in each of the two entities - 2,400 households are from RS and 3000 from $\mathrm{FBiH}$. The two entities were formed as a result of the General Framework Agreement, also referred to as the Dayton Accord, which brought a halt to the conflict. The Federation of Bosnia and Herzegovina (FBiH) consists of 51 percent of the territory and the Republika Srpska (RS) covers the remaining 49 percent of the territory. FBiH is mostly populated by Bosniaks and Croats, who consist of almost 97 percent (72.5 and 24.4 percent, respectively) of the population in $\mathrm{FBiH}$, whereas Serbs constitute more than 93 percent of population in RS (Bisogno and Chong 2002).

The resulting data are representative by type of municipality: urban, rural, and mixed (semi urban) within each of the two entities. 25 municipalities were selected, out of which 14 were from FBiH and 11 from RS. Municipalities are described as urban if 65 percent or more of the households are considered to be urban; rural municipalities are those where the proportion of urban households is below 35 percent; the remaining municipalities were classified as mixed (State Agency for Statistics, Republika Srpska Institute of Statistics, Federation of BiH Institute of Statistics and World Bank, 2002a). "Municipalities were selected with probability proportional to estimated population size within each stratum, so as to select approximately $50 \%$ of the mostly urban municipalities, $20 \%$ of the mixed and $10 \%$ of the mostly rural ones" (State Agency for Statistics, Republika Srpska Institute of Statistics, Federation of BiH Institute of Statistics and World Bank, 2002a:7).

\section{Seven from Sub-Saharan Africa, three from Asia, and one from Latin America}

8 Given that the Herzegovina (LSMS) dataset was used for examining whether the incidence of poverty is greater amongst FHHs, we assume that all households that reported themselves as female-headed (self-reported headship definition) were taken as such in the study. 


\subsubsection{Overview of shares of different female-headship categories in the LSMS-BiH}

Given that the focal point of this study are female-headed households, an overview of the number and shares of different categories of FHHs in the total number of households from the LSMS 2001 is given in table 1. The category of self-reported FHHs is created according to the responses of interviewees in the LSMS 2001, where a self-reported household head is the person designated in response to the question: "Who is the head of your household?" (State Agency for Statistics, Republika Srpska Institute of Statistics, Federation of BiH Institute of Statistics and World Bank, 2002b). The household head is designated by the household members on the basis of their own criteria. Often, it is the person who provides for the family or who is aware of all the activities and affairs of the household. (State Agency for Statistics, Republika Srpska Institute of Statistics, Federation of BiH Institute of Statistics and World Bank, 2002b). Reported de jure $\mathrm{FHH}$ are generated when the self-reported FHHs are broken down by their marital status. Following Rogers (1995), the assumption in this study is that the concept of headship should be defined on the basis of economic support and that self- reported headship does not reliably identify the economic support base of the household. The concept of the major earner helps identify more clearly women that economically support households than does the idea of the reported head and, for this reason, this subgroup of households is extracted from the LSMS 2001 with shares presented below.

At the national level, self-reported female-headed households represent a quarter of all households included in the survey. A somewhat higher percentage of self-reported $\mathrm{FHHs}$ are located in $\mathrm{FBiH}$ (27.3 percent) compared to the smaller entity

\begin{tabular}{|l|}
\hline Self-reported FHH \\
\hline Reported widows \\
\hline Reported single women \\
\hline Reported divorced/separated women \\
\hline Reported married female heads \\
\hline Reported FH living with a male partner \\
\hline Reported major female earners \\
\hline Total households in LSMS 2001 \\
\hline
\end{tabular}

\begin{tabular}{|r|}
\hline Nationwide \\
\hline $1345(24.90 \%)$ \\
\hline $1044(19.33 \%)$ \\
\hline $107(1.98 \%)$ \\
\hline $113(2.09 \%)$ \\
\hline $65(1.20 \%)$ \\
\hline $13(0.24 \%)$ \\
\hline $32(0.59 \%)$ \\
\hline 5402 \\
\hline
\end{tabular}

(21.8 percent), and the statistical test indicates that this difference is significant. 27 percent of households in urban areas are headed by women, while these have somewhat smaller shares in mixed and rural municipalities (23 and 21 percent, respectivelly). The shares of FHHs in urban, mixed, and rural municipalities are broadly proportionate to the shares of the total number of households from the survey in these municipalities. Table 1 also presents the shares of different categories of $\mathrm{FHHs}$, based on six additional definitions of $\mathrm{FHH}$, in the total number of households covered by the LSMS 2001. In particular, reported widows are the largest category, accounting for more than 19 percent of the total households in the survey. Also, households headed by widows represent 77 percent of the total number of self-reported female-headed households. Although more than a third of self-reported widows belong to the age range between 35 and 60 years old, i.e. they were likely to be married in 1991, and assuming that their husbands were approximately the same age, i.e. they are likely to have been mobilised in the war, there is not enough evidence to conclude that the recent war is the main cause for such a large number of widows in Bosnia and Herzegovina. The share of widows in the adult female population in Bosnia and Herzegovina ${ }^{9}$ is 19 percent and is considerably lower than that in countries recently involved in civil wars, such as Rwanda and Mozambique, where over 70 percent of adult women are widowed (Owen, undated). Bosnia and Herzegovina rather follows the trends of other South-Eastern European countries that were not affected by a war, such as Bulgaria, where widows comprise more than 14 percent of adult female population (National Statistical Institute of Bulgaria 2006). In addition, the evidence indicates that women have traditionally outlived men in $\mathrm{BiH}^{10}$ (UNDP 2002).

\section{Calculated based on LSMS 2001}

${ }^{10}$ Average life expectancy is 74.8 for wom. and 70.8 men.

\begin{tabular}{|r|}
\hline FBIH \\
\hline $821(27.3 \%)$ \\
\hline $640(21.3 \%)$ \\
\hline $62(2 \%)$ \\
\hline $67(2.2 \%)$ \\
\hline $44(1.5 \%)$ \\
\hline $7(0.2 \%)$ \\
\hline $27(0.9 \%)$ \\
\hline 3002 \\
\hline
\end{tabular}

\begin{tabular}{|r|}
\hline \multicolumn{1}{|c|}{ Urban } \\
\hline $804(26.79 \%)$ \\
\hline $598(19.93 \%)$ \\
\hline $71(2.37 \%)$ \\
\hline $75(2.50 \%)$ \\
\hline $49(1.63 \%)$ \\
\hline $8(0.27 \%)$ \\
\hline $23(0.77 \%)$ \\
\hline 3001 \\
\hline
\end{tabular}

\begin{tabular}{|r|}
\hline \multicolumn{1}{|c|}{ Mixed } \\
\hline $312(23.41 \%)$ \\
\hline $252(18.90 \%)$ \\
\hline $23(1.73 \%)$ \\
\hline $22(1.65 \%)$ \\
\hline $12(0.90 \%)$ \\
\hline $3(0.23 \%)$ \\
\hline $3(0.23 \%)$ \\
\hline 1333 \\
\hline
\end{tabular}
Rural $229(21.44 \%)$ 194(18.16\%) $13(1.22 \%)$ $16(1.50 \%)$ $4(0.37 \%)$ 2(0.19\%) $6(0.56 \%)$ 1068

\section{Table 1}

Number and shares of different female headship categories in total number of households in the LSMS 2001 
Furthermore, there are 107 single female heads and 113 divorced or separated female heads of households; each of these categories represents around 2 percent of the total number of households reported in the survey. Moreover, two thirds of single female heads and the same share of divorced or separated female heads of households live in urban type settlements in $\mathrm{BiH}$. This is as expected given that the stability of marriages is weaker and the trend of women living on their own is more common in urban than in rural areas as a result of more economic opportunities and less traditional social norms that constrain women in the former (Chant 1997).

There are no de facto female-headed households-i.e. those self-reported FHHs where the reported head has a spouse or common-law partner who has not been physically present for longer than nine months ${ }^{11}$ - in the dataset. Given that Bosnia and Herzegovina is quite a patriarchal society, with feminist ideas and practices still in their infancy, it is not surprising that only 1.2 percent of married women who live with their spouses are reported as household heads out of the total number of households covered by the survey. As expected, for the reason given above, 75 percent of these live in urban municipalities. Although married female heads of household are more likely to work than the spouses of male heads, Kukanesen (2003) argues that economic criteria alone do not explain the preference for males in Bosnia and Herzegovina, given that half of married male heads and half of married female heads do not work. In addition, the number of women who are reported as head of the household and who have unmarried or common-law partners is extremely low- only 13 out of 1345 , representing 0.24 percent of interviewed households.

Finally, the number of women who earn more than 50 percent of the annual household income and are, according to the economic definition, designated as head of the household, is not large - only 32 of this type of household, which is less than 0.6 percent of the total households interviewed at the national level. Unsurprisingly, around 70 percent of these households come from urban municipalities in the Federation of Bosnia and Herzegovina that offer a greater spectrum of opportunities in the labour market. Interestingly, almost 85 percent of female major income earners are from $\mathrm{FBiH}$, which is likely a consequence of its better economic situation and higher wages (State Agency for Statistics for BiH 2006) compared to RS.

\subsection{Social policies relevant to the state of FHHs in Bosnia and Herzegovina}

Households in Bosnia and Herzegovina were the recipients of international aid immediately after the war that disappeared in later years. Nowadays, households in need receive benefits in the form of public transfers that assist them in coping with poverty. There are some non-governmental organisations whose major beneficiaries are women, as well as financial institutions that offer special financing schemes that target women; this section, however, will focus on public transfers only.

The social security system in Bosnia and Herzegovina is decentralised due to the specific constitutional framework of the country. Although each entity has social security regulated by separate laws, both are similar in terms of eligibility for social security and its procedures through which such benefits can be obtained (Obarčanin 2005). Amongst other things, these laws regulate the following areas that might have a direct relation to the welfare of female-headed households: social security of citizens and their families, and the rights of war victims and their families.

The pension system has an important role in safeguarding the elderly from poverty in Bosnia and Herzegovina. The legal retirement age for women is 65 years in $\mathrm{FBiH}, 60$ years in the RS and 65 years for men in both entities. The average pension amounted to $145 \mathrm{KM}$ on the national level in 2001. The level of pensions in the RS was notably lower than that of the $\mathrm{FBiH}$ in 2001 in particular: in $\mathrm{FBiH}$ it was $170 \mathrm{KM}$ and in RS 105KM. Both entities introduced a minimum pension that has been fixed at $80 \mathrm{KM}$ in $\mathrm{RS}$ and $140 \mathrm{KM}$ in $\mathrm{FBiH}$. In addition, both entities have benefits to which 'the surviving spouse' (the widow or the widower), "the divorced spouse, if awarded the support right by the Court, and children born within or out of wedlock, adopted, stepchildren supported by the insured, grandchildren, and other children without parents who were supported by the insured until his death" (Obarčanin 2005:11) are entitled. A widow is entitled to benefits if she is aged 45 or over and a widower if he is aged 55 in RS and 60 in $\mathrm{FBiH}$ and/or if they care for children entitled to survivor's pension or if they are disabled (Official Gazette RBIH, No. 2/92). In the case of remarriage, a widow aged less than 45 or widower less than 55 years in RS or 60 in $\mathrm{FBiH}$ will no longer be entitled to a survivor's pension, unless totally incapable of work (Obarčanin 2005). The survivor's pension is calculated as a percentage of the pension to which

11 Absence of a spouse for longer than 9 or 12 months is usually taken as a norm in defining de facto male- or female-headed households 
the deceased would have been entitled and according to the number of eligible survivors (one survivor $70 \%$, two survivors $80 \%$, three survivors $90 \%$, four or more survivors $100 \%$ ). In addition, the members of families of fallen soldiers are beneficiaries of social health insurance and are given priority in obtaining housing (Official Gazette RBIH, No. 2/92). Benefits provided for household survivors will be assessed in the later analysis against the welfare of this particular group of households.

The state also provides financial support to families with children whose income is below average earning level in $\mathrm{FBiH}$ and whose monthly income per family member is lower than 56.03 KM in RS. Child benefits, however, have been terminated in the majority of cantons in $\mathrm{FBiH}$, which halved the number of children covered by these between 1998 and 2000 (World Bank 2003). However, neither entity has provisions in terms of an allowance for single parents (Obarčanin 2005). There are also unemployment insurance systems, adopted by both entities, which provide a modest system of income support to the unemployed. The duration of eligibility depends on the number of years of work experience and ranges from 6 to 12 months in the $\mathrm{FBiH}$, and from 3 to 12 months in RS.

As this overview of the policies implies, there is a significant amount of 'categorical'transfers i.e. pensions and veterans' benefits that are of importance for the welfare of some categories of FHHs, such as widows and some mothers who are heads of households. However, most of the categories of FHHs are not explicitly covered by the social policies.

\subsection{Female labour force participation in Bosnia and Herzegovina}

The position of Bosnia and Herzegovina in transition to a market economy was not only unique because of the economic transformation typical of all transitional countries in the South Eastern Europe, but because it was burdened by political instability and the severe consequences of the war. Bosnia and Herzegovina, similar to other socialist countries, was characterised by 'labour hoarding' i.e. "employment above the technically efficient level" (Mickiewicz 2005:84). The 'equality for all' maxim imposed high female employment rates and the equal treatment of men and women in the labour market, although some authors argue that equality in practice was as absent in communism as much as it is in capitalism (Vaknin 2002). This resulted in higher female labour force participation that was supported by a number of programmes, such as day care centres, nurseries, daylong schools, and abortion clinics facilitating their participation, as well as in a lower gender pay gap com- pared to industrialised market economies (Fong and Lokshin 2000; Paci 2002).

Nevertheless, women's participation in the labour market in Bosnia and Herzegovina plummeted in the post-war years and this is likely to be due to the many cuts in public services that women had access to before the war. Also, the general labour market conditions and increased gender inequality in the post-war period depressed female participation (Paci 2002). The privatisation of state-owned enterprises was dominated by male managers and insiders, neglecting gender equality and further deepening the labour force participation gap (Vaknin 2002). Given that the real value of earnings decreased, it is likely that the substitution effect dominates the income effect, i.e. low wage workers may decide to withdraw from the labour market as leisure becomes a cheap commodity. In addition, Mickiewicz (2005:87) argues that a part of the reason for a decrease in activity rates lies in "natural adjustment in activity rate, following the dismantling of the command economy system" and higher incentives to obtain higher education under the 'new' market system.

Furthermore, formal employment plummeted during the war and stayed rather constant in the years after the war, whilst informal employment is suspected to have increased due to structural modifications of the markets, demographic changes, and the widespread destruction of factories and industrial premises. These changes caused a drop in the standard of living and an increase in poverty (Bisogno and Chong 2002; Paci and Reilly undated). In the absence of exact data on the informal sector, figure 1 gives an overview of the employment in the formal sector in the pre-war and post-war period. Kukanesen (2003) argues that there is a large informal sector in $\mathrm{BiH}$, consisting of 36 percent of the total employment.

The economic activity rate is a key indicator of the labour market participation and represents the percentage of individ-

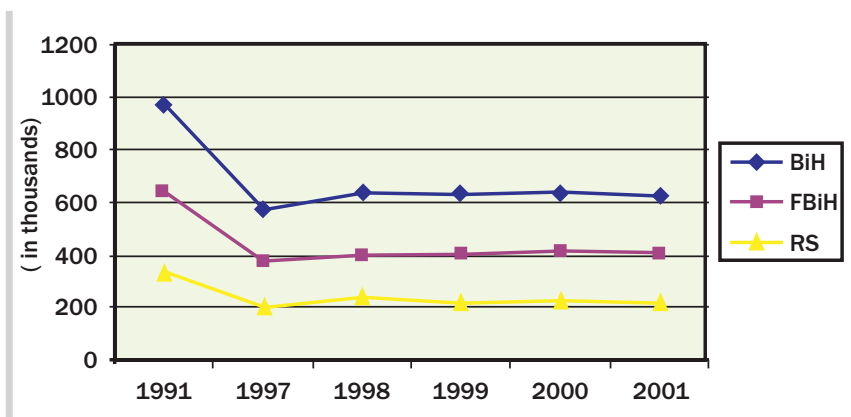

Source of data: Statistical Yearbook 2001, Federal Office of Statistics, Sarajevo; Statistical Yearbook of the Republic of BiH 1992, Federal Office of Statistics, Sarajevo; Republic of Srpska Institute of Statistics, Banja Luka, 2000.

Figure 1.

Formal employment 1991 and 1997-2001 
uals considered economically active ${ }^{12}$ in the total working age population (ILO definition) or the proportion of the specified group supplying labour for the production of economic goods and services during a specified period (UNDP 2002). Economic activity rates in 2001 in Bosnia and Herzegovina (hereafter $\mathrm{BiH}$ ), presented in table 2, suggest there was a decrease in the labour force participation rates of both, men and women, in the last decade.

In particular, activity rates that were around 65 percent and 80 percent for women and men respectively in 1990 (Paci and Reilly undated) dropped to 35 percent for women and 68 percent for men in 2001. The female economic activity rate in Republika Srpska is 38 percent and is slightly higher than that in the $\mathrm{FBiH}$ (31 percent). This is rather unusual given that $\mathrm{FBiH}$ had higher average wages in the period from 1997 to 2001 and that higher wages normally stimulate female participation (Jaumotte 2003). The possible reason might lie in higher taxes on wages in $\mathrm{FBiH}$ compared to RS and the lower absolute value of social benefits in RS that, as Mickiewicz (2005) suggests, may result in workers sticking to their jobs. What is striking is that the economic activity rates of men are very similar in both entities and this trend persists across rural, urban and mixed types of settlements. Moreover, the economic activity rates of women stay significantly lower than the rates of men when calculated for the whole of $\mathrm{BiH}$, as well as when disaggregated by entity and by types of settlement. As expected, the highest labour force participation of women is in urban areas, followed by mixed and rural municipalities. The likely reason for such an outcome is that more economic opportunities are available in urban- typically more developed-regions. Despite the participation of female heads of households in the labour force being somewhat higher than that calculated for all economically active females, it is still modest relative to the same figures in other Balkan countries presented in the study of Vodopivec from 2002. Moreover, the labour market participation of female heads is higher in RS than in FBiH. Breaking down economically active men and women into those who are employed and unemployed gives the following rates, as shown in table 2. The employment rates of economically active men and of those who are heads of households are higher than those of their female counterparts on both the national and entity level. The analysis indicates that the opposite is true when calculations of unemployment rates for the same categories are performed. Unemployment rates of all economically active women are somewhat higher than that of economically active female heads. Moreover, unemployment rates in RS are lower for all economically active women, as well as for female heads of households, compared to those in FBiH. Finally, employment rates are higher for women who are heads of households compared to those of all women.

12 The economically active population is defined as all adults between 15 and 64 who were in employment at any time during the week prior to Census night, or unemployed, but seeking work or waiting to take up a job, or intending to seek work but temporarily sick (ILO).

\begin{tabular}{|c|c|c|c|c|c|c|}
\hline & BiH & RS & FBIH & Urban & Mixed & Rural \\
\hline \multicolumn{7}{|c|}{ Economic Activity Rates * } \\
\hline Females & $35 \%$ & $38 \%$ & $31 \%$ & $38 \%$ & $35 \%$ & $30 \%$ \\
\hline Female heads & $36 \%$ & $44 \%$ & $32 \%$ & $39 \%$ & $36 \%$ & $35 \%$ \\
\hline Male & $58 \%$ & $60 \%$ & $56 \%$ & $60 \%$ & $58 \%$ & $55 \%$ \\
\hline Male heads & $68 \%$ & $68 \%$ & $67 \%$ & $70 \%$ & $64 \%$ & $63 \%$ \\
\hline \multicolumn{7}{|c|}{ Employment* } \\
\hline Females & $27 \%$ & $30 \%$ & $24 \%$ & $24 \%$ & $22 \%$ & $20 \%$ \\
\hline Female heads & $30 \%$ & $35 \%$ & $27 \%$ & $32 \%$ & $26 \%$ & $29 \%$ \\
\hline Male & $53 \%$ & $55 \%$ & $50 \%$ & $53 \%$ & $53 \%$ & $50 \%$ \\
\hline Male heads & $65 \%$ & $66 \%$ & $64 \%$ & $67 \%$ & $64 \%$ & $60 \%$ \\
\hline \multicolumn{7}{|c|}{ Unemployment* } \\
\hline Females & $17 \%$ & $18 \%$ & $16 \%$ & $15 \%$ & $18 \%$ & $18 \%$ \\
\hline Female heads & $15 \%$ & $18 \%$ & $14 \%$ & $10 \%$ & $14 \%$ & $16 \%$ \\
\hline Male & $15 \%$ & $16 \%$ & $17 \%$ & $15 \%$ & $16 \%$ & $16 \%$ \\
\hline Male heads & $12 \%$ & $13 \%$ & $10 \%$ & $8 \%$ & $9 \%$ & $10 \%$ \\
\hline
\end{tabular}

Table 2

Economic Activity Rates segregated by gender and headship in 2001** 


\subsubsection{Empirical analysis of the determinants of female labour force participation}

Conventional economic analysis argues that labour force participation is affected by the difference between the market wage and the reservation wage, where there is a positive relation between the market wage and the decision to work. A probit model, with standard errors corrected for heteroscedasticity, was used to estimate women's decision to join the labour force, given that the dependent variable gives a dichotomous choice. The dependent variable is a dummy variable and is equal to one if the individual is either employed or unemployed but looking for a job and equal to zero if the individual is neither working nor actively looking for work. Given that the market wage depends on individual and demographic characteristics, as well as on geographical region (Anderson and Pomfret 2000), the characteristics of working age women ${ }^{13}$, such as age, education, marital status, relationship to the head of household, as well as entity and type of municipality they live in were controlled for. Variables controlling for age and agesquared are included in the model in order to estimate how and to what extent different ages in the household head affect the decision to join the labour market. Apart from marital status, the number of children ${ }^{14}$ also determines the reservation wage and, for this reason, was included in the model. Dummy variables were created for education, entity, types of municipality, female headship, and marital status. The omitted base categories for these dummy variables are, correspondingly: no completed education, RS, urban municipalities, women who are not the head of household, and single women. Theoretically, the expectation is that female labour force participation (hereafter FLFP) will increase with human capital and decrease with marriage and a greater number of children (Anderson and Pamfret 2000). Single women are likely to be in the labour force because in our sample they are relatively well educated and a minority of them have children. FLFP is expected to increase with age until a certain point, after which it is expected to decrease. Moreover, although female heads of households tend to have relatively high inactivity rates compared to male heads, our expectation is that female heads will be either associated with higher labour force participation compared to women who are not heads or that there will be no statistical difference between the two. The reason is relatively generous social benefits provided for widows, who make up the majority of female heads in the sample under investigation. Finally, the labour force participation of women in urban municipalities is expected to be higher compared to the rest of the municipalities; however, there is no clear expectation with respect to entities.
The estimation results are given in table $3^{15}$.

\begin{tabular}{|c|c|}
\hline \multirow[t]{2}{*}{ Age } & 0.261 \\
\hline & $(0.000)^{* * *}$ \\
\hline \multirow[t]{2}{*}{ Age $^{2}$} & -0.007 \\
\hline & $(0.000) * * *$ \\
\hline \multirow[t]{2}{*}{ Female Heads } & -0.114 \\
\hline & -0.472 \\
\hline \multirow[t]{2}{*}{ Legally married } & -0.299 \\
\hline & $(0.000)^{* * *}$ \\
\hline \multirow[t]{2}{*}{ Live together } & 0.251 \\
\hline & $(0.054)^{*}$ \\
\hline \multirow[t]{2}{*}{ Widows } & -0.08 \\
\hline & $(-0.774)$ \\
\hline \multirow[t]{2}{*}{ Separated or divorced } & 0.352 \\
\hline & $(0.011) * *$ \\
\hline \multirow[t]{2}{*}{ No. of children $<14$} & -0.134 \\
\hline & $(0.000) * * *$ \\
\hline \multirow[t]{2}{*}{ Completed primary education } & 0.622 \\
\hline & $(0.000)^{* * *}$ \\
\hline \multirow[t]{2}{*}{ Completed secondary education } & 1.284 \\
\hline & $(0.000)^{* * *}$ \\
\hline \multirow[t]{2}{*}{ Higher education, university diploma or higher } & 2.103 \\
\hline & $(0.000)^{* * *}$ \\
\hline \multirow[t]{2}{*}{ FBiH } & 0.101 \\
\hline & $(0.017)^{* *}$ \\
\hline \multirow[t]{2}{*}{ Mixed municipality } & 0.122 \\
\hline & $(0.007)^{* * *}$ \\
\hline \multirow[t]{2}{*}{ Rural municipality } & 0.163 \\
\hline & $(0.000) * * *$ \\
\hline \multirow[t]{2}{*}{ Constant } & -6.247 \\
\hline & $(0.000)^{* * *}$ \\
\hline \multicolumn{2}{|l|}{ Observations 5612} \\
\hline Robust $p$ values in parentheses & $(0.000)^{* * *}$ \\
\hline \multicolumn{2}{|c|}{ * significant at $10 \% ; * *$ significant at $5 \% ; * * *$ significant at $1 \%$} \\
\hline Pseudo R2 $=0.2337$ & \\
\hline
\end{tabular}

\section{Table 3.}

Probit model of female labour force participation in 2001

\section{Aged between 15 and 64.}

14 This measure may include dependent children that are not the direct offspring of the woman.

15 In our analysis, only the signs on estimated coefficients and their significance are interpreted whereas probabilities are not calculated. 
The estimated coefficients on human capital characteristics support the a priori assumption, i.e. the coefficients on dummies for the level of education suggest that the labour force participation is, on average, likely to be significantly higher amongst women who hold a school diploma compared to those who do not have any education, other things being equal. In particular, the higher the level of education, the higher its coefficient. Furthermore, ceteris paribus, estimated coefficients on age, age and number of children under 14 are significant at 1 percent and their signs confirm the expectations. The negative coefficient on age-squared suggests that women, after a certain age, are more likely to be dependent on social benefits, i.e. pension. Furthermore, the coefficient on the dummy for married women suggests that these are, on average, less likely to join the labour force compared to single women, other things being equal (significant at the 1\% level). Given that a small number of single women in the sample under investigation have children, a variable that is normally negatively associated with the female labour force participation, this is probably the reason for their relatively higher participation. The coefficients on the dummy for separated and divorced women and women who live with unmarried and common law partners indicate that the situation is likely to be the opposite of that of married women. Furthermore, the estimated coefficient on the dummy for widows suggests that, on average, there is no statistical difference between them and single women in terms of the decision to participate in the labour force, other things being equal.

A particularly interesting result is that, ceteris paribus, women living in $\mathrm{FBiH}$ are, on average, significantly more likely to participate in the labour market compared to women from $\mathrm{RS}$, which is in contrast with the figures in table 2 that show a lower FLFP in FBiH than in RS. At least a part of this disagreement in the estimation outcome is perhaps caused by not controlling for the tax on wages, which is somewhat higher in $\mathrm{FBiH}$ than in RS. Furthermore, estimated coefficients on dummies for rural and mixed municipalities do not seem to support the a priori expectation. These suggested that women from rural and mixed municipalities are more likely to join the labour force than women from urban municipalities in Bosnia and Herzegovina, other things being equal. Greater availability of employment opportunities in the agricultural sector in the municipalities with lower level of urbanisation is probably a part of the reason for such a result. Finally, female headship does not seem to exhibit a positive significant impact on female labour force participation in Bosnia and Herzegovina, i.e. women who are heads of households are not, on average, more likely to join the labour force participation than those who are not heads of households, other things being equal. Hence, our empiri- cal analysis indicates that female headship is not a significant determinant of the decision to join the labour force, possibly because widowed heads are the biggest category of self-reported female-headed households and are provided with relatively generous social benefits by the state compared to other female heads.

\section{Empirical analysis of the consumption dimension of poverty amongs female-headed households}

\subsection{Analysis and comparison of poverty in FHHs and MHHs}

A general poverty line is an absolute poverty line and is based on the concept that food is not the only good required by a household. There is no accepted criterion for creating a general poverty line, for the reason that it is very subjective as to the extent of non-food needs. However, patterns of consumption in the population can be used to calculate an allowance for essential non-food spending that is added to the value of the basic food level. It has been calculated that the general poverty line in Bosnia and Herzegovina in 2001 amounted to 2198.18 KM (Convertible Mark) per capita (State Agency for Statistics, Republika Srpska Institute of Statistics, Federation of $\mathrm{BiH}$ Institute of Statistics, World Bank 2002). Yearly household consumption per capita, adjusted for regional differences in prices, was used to calculate which households fall below this general poverty line. Following Lanjouw et al (1998), the relative poverty risks of different demographic subgroups of the population change depending on the economy of scale parameter used, given that larger families may take advantage of significant economies of scale, that children normally consume less than adults in a household and that FHHs are often of smaller size compared to MHHs. Tests were carried out in 'Welfare in Bosnia and Herzegovina, 2001: Measurement and Findings' (State Agency for Statistics, Republika Srpska Institute of Statistics, Federation of BiH Institute of Statistics, World Bank 2002), using BiH LSMS 2001 data- i.e. the data employed in our analysis- in order to find out which equivalence scale is the most appropriate. The obtained test statistics did not indicate that there are grounds to accept one equivalence scale over another and, hence, per capita scale was used throughout the analysis.

Table 4 gives the percentages of Bosnian households whose consumption is below the general poverty line. Households are broken down according to the different definitions 
of household headship, as presented in table 3, and are disaggregated by entity, by type of settlement and by gender within each of the headship definitions.

The analysis indicates that a significantly smaller percentage of self-reported FHHs and reported households headed by widows is below the general poverty line compared to the same categories of MHHs in Bosnia and Herzegovina, in both entities and on each level of municipality urbanization under investigation (urban, mixed and rural). Further analysis shows that significantly smaller percentage of households with reported married female heads, compared to households headed by married men, have consumption lower than 2198.18 KM at the national level, in $\mathrm{FBiH}$ and in urban areas. Also, reported households headed by single females seem to be better-off than households headed by single males at the national level only, while when these households are broken down by entity and municipality level, no statistically significant difference was found between the two. FHHs and $\mathrm{MHH}$ s whose heads live with unmarried or common-law partners do not appear to be significantly different in terms of consumption dimension of poverty except in RS, where more FHHs from this sub-group are below the general poverty line than their MHHs counterparts. However, one should be cautious when interpreting this estimation, as the sample of households whose heads live with unmarried or common-law partners is rather small. Additionally, a comparison between households with separated or divorced male and female heads, although suggesting that $\mathrm{MHH}$ are more likely to be poor, does not demonstrate statistically significant differences between male- and FHHs households.

Departing from self-reported and demographic headship criteria and adopting the economic definition of headship indicates that this sub-group of $\mathrm{FHH}$ is significantly less poor than

\begin{tabular}{|l|}
\hline Self-reported heads / Reported de jure heads \\
\hline Reported widowed \\
\hline Reported single \\
\hline Reported divorced/separated \\
\hline Reported married head \\
\hline Reported Heads living with a partner \\
\hline Reported major female earners \\
\hline
\end{tabular}

MHHs. This finding is in line with Fuwa (1999)'s, Rogers (1995)' and Handa (1994)'s findings from Panama, the Dominican Republic and Jamaica, respectively, where FHHs, created on the basis of economic support, are found to be better-off compared to MHHs. Our finding is of particular importance viewed in the light of the argument presented earlier in this study; in particular, the recipients of anti-poverty interventions should be household member(s) recognised as those who bring most benefit, in economic terms, to the household. Given that our analysis based on the sample of 5401 households from Bosnia and Herzegovina shows that FHHs primarily supported by female members are not worse-off than $\mathrm{MHH}$ s primarily supported by male earner(s) there is no justification for preference of $\mathrm{FHHs}$ over MHHs when targeting poor households. Nevertheless, further analysis of the consumption of FHHs is conducted in the next section in order to additionally investigate the welfare of $\mathrm{FHHs}$ and its determinants.

\subsection{Empirical analysis}

The analysis presented above indicates that the poverty of female-headed household varies with the headship definition applied, although most of the categories of FHHs are not found to be significantly more vulnerable to poverty than $\mathrm{MHH}$. An empirical analysis is conducted below to establish whether headship is a significant determinant of yearly per capita household consumption in order to further investigate the welfare of FHHs and factors that affect it. Separate analyses were undertaken for households with self-reported female heads that were further disaggregated into five self-reported and de jure categories of headship. Given that Bosnian society is quite traditional, especially in terms of female-male relations, we believe that self-reported FHHs do not give a full picture of the poverty of FHHs in the country. The picture of the poverty

Figures in bold designate cases where significantly lower share of FHHs than MHHs is below the general poverty line at $5 \%$ level of significance or lower.

Table 4.

Female- headed households below the general poverty line 
situation is particularly unclear and complicated when there is a male member of the household, who is normally reported as a household head due to social, religious and cultural norms, even in cases where a woman is the major earner and fully involved in the household's affairs and decision-making. For this reason, following the arguments of the recent poverty studies provided in section 2 of this study, the category of major household earner was created according to the economic definition of headship and included in the analysis.

Yearly household per capita consumption was taken as the dependant variable to describe the welfare of households in Bosnia and Herzegovina. Separate analyses were conducted for the national level, for each entity, and for urban, rural and mixed types of municipalities. Annual household per capita consumption was regressed on a dummy variable for headship whilst controlling for age of head of household, age-squared of head of household, number of children in household, dummy variables for the type of school diploma held by the head of household, and a dummy variable indicating whether a household member owns any land ${ }^{16}$. Variables controlling for age and age-squared are included in the model in order to estimate how and to what extent they affect household consumption with respect to the age of the household head. This will give a basis for the assessment of the pension system in Bosnia and Herzegovina in the last section. A dummy variable for a male headed household was taken as a base category and, hence, omitted from all the regression models. Three dummy variables for the type of diploma - primary school, secondary school, and university diploma (including 2, 4 year university diploma, master and doctoral diploma) - held by the head of household were included in the model. The omitted cat- egory were those households whose heads lack a diploma. A dummy variable indicating whether any household member owns land was included in the regression, where households without land owned were taken as a base category. In terms of expected signs and the statistical significance of the independent variables, a dummy for $\mathrm{FHH}$ is expected to have either a positive sign or to be insignificant given the findings in the previous section. Variables controlling for age and age-squared are expected to have significant positive and negative signs, respectively, while the dummies for education are likely to have a significantly positive effect on the yearly per capita household consumption. This effect is likely to be of particular importance in the case of women given that there is a statistically higher percentage of female married heads having a university diploma than male married heads. A variable controlling for number of children in the household normally exhibits a negative effect on household income and a variable controlling for land owned by a household is expected to have a significant positive sign in rural and mixed areas and to be insignificant for the consumption of households in urban municipalities.

In all of the regressions, except for the category designated in the table 5, semi-log OLS models were specified. The diagnostic tests do not give grounds for rejecting the assumptions of the Classical Normal Linear Regression Model in most of the regression models undertaken. A few specifications failed

16 It should be noted that in a few regressions some independent variables that were statistically insignificant were dropped for the sake of more satisfactory diagnostic tests. Dropping these variables did not significantly change the estimated coefficients on the rest of the independent variables.

\begin{tabular}{|c|c|c|c|c|c|c|}
\hline & Nationwide & FBiH & RS & Urban & Mixed & Rural \\
\hline Self-reported FHH / Reported de jure heads & $519.235^{3} * * *$ & $-0.218 * * *$ & $0.002 * * *$ & $0.163 * * *$ & $0.186 * * *$ & $80.1 * * *$ \\
\hline Reported widow head & $0.074 * *$ & .041849 & $.19750 *$ & .046061 & -.0627 & .193 ** \\
\hline Reported single female head & $.165 *$ & .089 & $.248 *$ & $0.239 *$ & .051 & .043 \\
\hline Reported divorced/separated female head & $-.204 * *$ & -.235 & -.183 & $-0.247 *$ & $-.1653^{4}$ & \\
\hline Reported married female head & -28.889 & 13.803 & -0.13 & $.164 * *$ & -0.105 & 0.276 \\
\hline Reported female head living with a partner & -.060 & $\mathrm{No}^{5}$ & .198 & .019 & No & No \\
\hline Reported major female earners & $.441 * * *$ & $.413 * * *$ & .781 & $.543 * * *$ & .214 & 1399.8 \\
\hline
\end{tabular}

* Significant at $10 \%$; * significant at $5 \%$; *** significant at $1 \%$

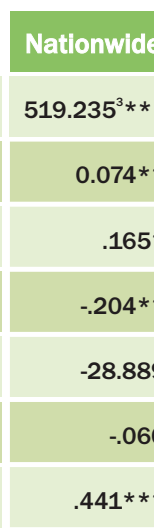

2 Coefficient estimates on control variables are not displayed here as the interpretation of the regression results does not refer to these, but details on each particular regression are available upon request.

Figures in italics represent the estimates of regression where the dependant variable is linear and, hence, should be interpreted in absolute terms.

Households from rural and mixed municipalities were merged in order to get a bigger sample for reported divorced/separated head category.

${ }_{5}$ No indicates there were not enough of observations i.e. the sample had fewer than 30 observations, to run a regression.

Table 5.

Estimated coefficients on headship dummy variables in yearly per capita consumption regression ${ }^{2}$ 
to meet the normality assumption, but the estimators are still the best linear unbiased estimators (BLUE) and the assumption of Linear Regression Model is not invalidated. In addition, given that the samples used for the estimation are large, it is possible to appeal to the Central Limit theorem, i.e.

\section{"if there are a large number of independent and identically distributed random variables, then, with a few exceptions, the distribution of their sum tends to a normal distribution as the number of such variables increases indefinitely".}

\section{(Gujarati 2003:109)}

Finally, since the recent literature argues that finding a suitable instrumental variable in order to control for the endogeneity problem is extremely difficult in cross-sectional datasets (Fuwa undated), instead of an instrument, a dummy variable for headship was included, an approach often applied in similar empirical analyses. Hence, the presented results need to be interpreted with caution. The coefficients on a dummy for female headship are presented in table 5.

The results of our empirical investigation shows that the estimated coefficients' signs on the dummies for female headship and their statistical significance vary with the definition of FHHs adopted. Overall, there are no grounds to argue that $\mathrm{FHHs}$ have on average lower per capita consumption than MHHs in Bosnia and Herzegovina, except in a few cases as described below. In particular, the analysis for self-reported FHHs suggests that these households have, on average, significantly higher yearly per capita consumption than MHHs nationwide, in RS, as well as in urban, mixed and rural municipalities, ceteris paribus. Interpretation of the estimate for $\mathrm{FBiH}$, under the same conditions, suggests that self-reported FHHs have a statistically significant 22 percent lower per capita consumption compared to the self-reported MHHs in this entity. Negative association between the female headship dummy and the household consumption in $\mathrm{FBiH}$ is likely to be a consequence of lower labour force participation, in the particular lower employment and higher unemployment rates of $\mathrm{FHHs}$ in this entity compared to RS, and by lower social allowance for children provided for families in need in FBiH compared to the other entity as suggested earlier in this study.

Further desegregation of self-reported FHHs by marital status shows a similar picture. On average, self-reported households with legally married female heads do not seem to have statistically different yearly household per capita consumption from male-headed households at the national level, in either entity or in the mixed and urban municipalities in Bosnia and
Herzegovina, other things being equal. Table 4 shows a statistically lower share of FHHs whose head is a legally married female under the general poverty line compared to their male head counterparts at the national level and in $\mathrm{FBiH}$; this somewhat conflicting result is probably a consequence of the effect of a variable(s) not included in the model. Informal employment is likely to be one of the factors affecting the consumption of households, as it provides women with earnings which, albeit low, are sufficient to keep them above the poverty line. In urban areas, however, our estimates suggest that households whose head is a married woman have, on average, statistically significant16.5 percent higher consumption than the same category of $\mathrm{MHH}$, other things being equal. This supports the figure in table 4, indicating that fewer FHHs are below the general poverty line compared to households with male heads with the same marital status.

Moreover, female heads that live with unmarried or common-law partners do not have significantly different yearly household consumption per capita than their male counterparts, ceteris paribus. This finding is in line with the figures in table 4 that show no statistical difference in the shares of male and female heads having an unmarried or common law partner that have consumption smaller than that of consumption at the general poverty line. It should be noted, however, that the results should be interpreted with caution given that the sample for this category of households was limited.

Ceteris paribus, reported households whose heads are single women, on average, have significantly higher yearly per capita consumption than male headed households with the same marital status in the whole country, RS and urban municipalities. In particular, the estimate suggests that this category of FHHs on the national level has, on average, 16.5 percent higher yearly per capita household consumption than single male head households, ceteris paribus. The difference is even higher in RS and in urban municipalities - on average 25 and 24 percent respectively in favour of $\mathrm{FHHs}$, other things being equal. This is in contrast to the findings of similar investigations for the transitional countries of Eastern Europe, where households headed by single women were found to have a smaller per capita consumption than the rest of households (Paci 2002).

Furthermore, the coefficients on de jure FHHs headed by widows are positive and statistically significant in estimated regressions for the whole country, in RS and in rural areas. These findings support the figures in table 4, which show that significantly fewer female widowed heads fall below the general poverty line, suggesting that this category of households is not disadvantaged in terms of consumption. Estimation outcomes 
for Bosnia and Herzegovina are in contrast with those from a similar analysis for developing countries, which found that households headed by widows are disproportionately represented amongst the poor (Ringen 2003; Joshi 2004; Gimenez 1987; Chen and Drèze 1995; Moghadam, 1993). The, somewhat privileged position of widows in Bosnia and Herzegovina compared to widows in most developed (European) and developing countries is likely to be due to rather generous benefits provided for widows ${ }^{17}$ by the Bosnian state.

In contrast, when the same analysis was conducted for heads of households who are divorced or separated, the estimated coefficients indicate a somewhat different position for $\mathrm{FHHs}$. Although the analysis in context of the general poverty line did not suggest a significant difference between the categories of male- and female-headed households, the empirical analysis indicates that this is the only category of $\mathrm{FHH}$ s that, on average, has lower consumption than the same type of $\mathrm{MHHS}$ nationwide and in urban areas, other things being equal. Given the rather high percentage of divorced and separated female heads with children in our sample, we suspect that a part of the reason for this outcome of our analysis might be related to difficulties when obtaining alimony. The International Helsinki Federation for Human Rights (undated: 91) argues that

"Before the war, such [alimony] court orders were sent directly to the defendant's employer, and the child support was deducted from his wages. Following the war, this system of enforcement has broken down since many people are illegally employed, i.e. not registered."

Finally, when the headship variable was created in accordance with the economic definition of headship, i.e. members of households who earn more than 50 percent of household's yearly consumption are denoted as household heads, regardless of what was reported in the survey, there was no evidence that FHHs are worse-off in terms of annual per capita consumption. At the national level, this category of FHHs has, on average, 44 per cent higher yearly per capita consumption than the same type of $\mathrm{MHH}$, ceteris paribus. In addition, the difference between households with male- and female major earner heads is somewhat smaller for the households in $\mathrm{FBiH}, 41$ percent in favour of $\mathrm{FHH}$ s on average, other things being equal. Although the coefficient on female headship in RS is positive and is even higher than that in $\mathrm{FBiH}$, in terms of yearly per capita consumption no statistical difference was found between female- and male-headed households. In addition, applying the same headship definition, the greatest difference between the consumption of FHHs and $\mathrm{MHH}$ is found in urban municipalities in Bosnia and Herzegovina, where the former has, on average, 54 percent higher yearly per capita consumption, ceteris paribus. An implication of these findings is that major female earners are more likely to have higher wages than major male earners ${ }^{18}$, at least at higher percentiles of wage distribution, and/or fewer children- which may also be relevant given our use of per capita consumption.

What particularly stands out in the analysis for urban municipalities is the implication that all categories of $\mathrm{FHHs}$, except those headed by separated or divorced women and by widows, have higher household consumption than $\mathrm{MHH}$. This can be explained by better employment opportunities in urban areas, which is a determinant, normally, positively associated with households' consumption.

Based on the results of the empirical analysis undertaken above, it can be argued that FHHs are, on average, better-off than MHHs in Bosnia and Herzegovina. The only potentially disadvantaged $\mathrm{FHH}$ are those living in $\mathrm{FBiH}$ and those headed by separated or divorced women. Nevertheless, the negative association between lower consumption and female headship disappear when economic support provided by women to households is taken into account.

17 Widowed spouses older than 45 automatically inherit the pension of their late spouse. Widows of soldiers killed in the war inherit pensions and additional financial benefits from the state.

18 The assumption is that if a woman is a major earner in a household, i.e. she provides more than half of the household income, she is probably at a rather high level of wage distribution i.e. her earnings in the labour market are amongst the highest of both men and women. 


\section{Concluding remarks, policy implications and recommendations for further study}

The empirical investigation conducted in this study does not suggest that headship is a useful concept in targeting the consumption aspect of poverty in Bosnia and Herzegovina. In general, we argue that, on average, the heterogeneous group of FHHs in Bosnia and Herzegovina is not more likely to have lower annual per capita consumption than $\mathrm{MHHs}$, other things being equal. Our findings suggest that the difference between FHHs and MHHs in terms of poverty is either statistically insignificant, or that a significantly lower percentage of FHHs are below the general poverty line compared to MHHs in Bosnia and Herzegovina. The empirical analysis of yearly per capita consumption of households generally confirms the finding that FHHs are not worse-off in terms of per capita consumption than MHHs in Bosnia and Herzegovina. Also, we find that the advantage of $\mathrm{FHHs}$ compared to $\mathrm{MHH}$ s within the context of per capita household consumption appears to be largely, although not exclusively, an urban phenomenon

What particularly stands out in the conducted analysis is that widowed female heads, which comprise 77 percent of selfreported FHHs, have a statistically lower incidence of poverty than male widowed heads in all of the analysed areas. We argue that this is due to the social benefits provided by the state, which are particularly favourable to the 'surviving spouse,' i.e. the widow or widower, compared to other subgroups of FHHs.

Hence, the implication of this research is that anti-poverty policies should not consider headship when targeting poor households. Policies designed to combat poverty can be in the form of financial support or programmes designed to integrate the poor into the labour market, whilst also increasing their productivity. Particular efforts in Bosnia and Herzegovina are required in the area of labour market participation, which is low- particularly amongst women- compared to the EU and other Balkan countries' rates. Increasing female labour force participation would entitle a greater number of women to pensions upon retirement, which would decrease the number dependent on social benefits. Given that the number of children is a variable robustly negatively associated with household income, we argue that child allowances should be enhanced and retargeted towards households in need with one or both parents. Also, although it is a politically sensitive issue, the veterans' benefit legislation needs reform in order to rationalise spending and focus on needy beneficiaries.

Undoubtedly, more research is necessary to fully examine the link between poverty and households headship. Poverty is a multidimensional phenomenon that can be measured in several ways and this study covers one dimension of poverty - the households' consumption. Further research is required to discover the position of households in Bosnia and Herzegovina, in particular FHHs, with respect to poverty when alternative, human development measures, such as health, education, accommodation or infrastructure are used. Also, the endogenity issue was neglected in our study for the reason that we had no valid instrumental variable available.

Nevertheless, our analysis of the consumption amongst the heterogeneous group of FHHs found that, principally, they are not poorer in terms of the consumption dimension of poverty compared to MHHs. Therefore, it could be argued that, despite a somewhat adverse economic situation in the country, there is no need for anti-poverty interventions targeting $\mathrm{FHHs}$ in Bosnia and Herzegovina. 


\section{References}

Agarwal, B., 2001, 'Poverty in a globalizing world at different stages of women's life cycle', UN Expert Group Meeting on Gender and Poverty, Institute of Economic Growth.;

Alderman H, P. A. Chiapporir L. Haddad, J. Hoodinott et R. Kanbur,1995, 'Unitary versus Collective Models of the Household: Is It Time to Shift the Burden of Proof', World Bank Research Observer, vol. 10, pp. 1-19;

Anderson, K., And Pomfret, R., (2000), 'Gender Effects of Transition:

The Kyrgyz Republic' draft; paper presented at the American Economics Association conference in New Orleans in January 2001;

Barros, R., Fox L. M and Mendonca R, 1994, 'Female-headed Households, Poverty and the Welfare of Children in urban Brazil', Policy Research Working Paper No.1275. The World Bank;

Bisogno M. and Chong A., 2002, 'On the Determinants of Inequality in Bosnia and Herzegovina, Economics of Transition 10(2), 301-337;

Blackburn R. M., Bradley B. and Jarman J., 2001, 'The Gendering of Work around the World: Occupational Gender Segregation and inequality'. Cambridge Studies in Social Research, No 8. Cambridge University Sociological Research Group: SRG Publications;

Bridge, 1995, 'A quarterly update from Bridge, raising gender awareness amongst policy makers and practitioners, Issue 2: Poverty Reduction Strategies'. Institute of Development Studies 1995 ISSN 1358-0612;

Bridge, 1997, 'Gender Inequality and Poverty: Trends, Linkages, Analysis and Policy Implications'. Report prepared for the Gender Equality Unit, Swedish International Development Cooperation Agency (Sida) by Sally Baden with Kirsty Milward;

Bridge, 2001, Briefing Paper on the 'Feminisation of Poverty', prepared for the Swedish International Development Cooperation Agency. Bridge Report No.59. Sussex: Institute of Development Studies;

Buhmann, B, Rainwater, L, Schmaus, G, Smeeding, T, M, 1988, 'Equivalence Scales, Well-Being, Inequality, and Poverty: Sensitivity Estimates across Ten Countries Using the Luxembourg Income Study (LIS) Database', Review of Income and Wealth, Blackwell Publishing, vol. 34(2), pages 115-42, June;

Buvinic, M., 1990, 'The Vulnerability of Women - Headed Households: Policy Questions and Options for Latin America and the Caribbean', Economic Commission for Latin America and the Caribbean. Meeting on Vulnerable Woman. 26 - 30 November. 1990. Vienna: UN;

Buvinic, M. and Gupta, G.R., 1997, 'Female headed house- holds and female-maintained families: are they worth targeting to reduce poverty in developing countries?' Economic Development and Cultural Change, Vol 45 No 2

Chant, S., 1997, 'Women-headed Households: Diversity and Dynamics in the Developing World', Houndmills, Basingstoke: Macmillan;

Chen, M. And Dreze J., 1995, 'Recent research on widows in India: Workshop and conference report. Economic and Political Weekly (Bombay). pp. 2435-2450.

Degraff, D. S., and Bilsborrow, R. E.,1992, 'Female-headed households and family welfare in rural Ecuador', Paper presented at the 1992 meetings of the Population Association of America, 30 April - 2 May, Denver, Colo., U.S.A;

Dreze, J. and Srinivasan, P.V, 1997, 'Widowhood and Poverty in Rural India: Some Inferences from Household Survey Data', Journal of Development Economics, 54, 217-234;

Fong, M. and Lokshin, M, 2000, 'Child Care and Women s Labor Force Participation in Romania', The World Bank Development Research Group Poverty and Human Resources Policy Research, Working Paper 2400;

Foster, A., 1993, 'Household Partition in Rural Bangladesh', Population Studies, 47(1);

Foster, A. D. and Rosenzweig, M. R., 2001, 'Household Division And Rural Economic Growth', Pier Working Paper No. 01-049;

Fuwa, N., 1999, 'The Poverty and Heterogeneity amongst Female Headed Households Revisited: The Case of Panama', Chiba University, Matsudo;

Fuwa, N., undated, 'A Note on the Analysis of Female Headed Households in Developing Countries', Agricultural Economics Department, Faculty of Horticulture, Chiba University;

Gammage, S., 1989, 'The Gender Dimension of Household Poverty: Is Headship Still a Useful Concept?' International Center for Research on Women;

Gangopadhyay, S., and Wadhwa, W., 2003, 'Are Indian Female-Headed Households More Vulnerable to Poverty?' India Development Foundation;

Garfinkel, I. and McLanahan, S., 1986, 'Single mothers and their children: A new American dilemma?' Washington D.C.: Urban Institute Press;

Gimenez, M., 1987, 'The feminization of poverty: Myth or reality?' Insurgent Sociologist, 14, (3), pp. 5-30.

Gonzalez, P., Santos, M.C., and Santos, L.D., 2005, 'The Gender Wage Gap in Portugal: Recent Evolution and Decomposition', CETE Discussion Papers 0505, Universidade do Porto, Faculdade de Economia do Porto; 
Gujarati, D., 2003, 'Basic Econometrics'. Fourth Edition. New York: McGraw-Hill Higher Education;

Handa, S., 1994, "Gender, Headship and Intra-household Resource Allocation”, World Development 22(10): 1535-47;

International Helsinki Federation For Human Rights, undated, 'Bosnia and Herzegovina', accessed on http://www.ihfhr.org/viewbinary/viewdocument.php?doc_id =2054\#search $=\% 2$ 2alimony\%20in\%20bosnia\%22 on 28th August 2006;

International Labour Organisation (ILO), 1996, 'The Feminisation of Poverty', accessed on http://www.ilo.org/public/english/bureau/inf/pkits/women3.htm on 26 June 2006;

Jackson, C.,1996, 'Rescuing Gender from the Poverty Trap', World Development, 24:3, 489-504;

Jaumotte, F., 2003, 'Female Labour Force Participation: Past Trends and Main Determinants in OECD Countries', OECD Economics Department Working Papers, No. 376, OECD Publishing;

Joshi, S., 2004, 'Female Household-Headship in Rural Bangladesh: Incidence, Determinants and Impact on Children's Schooling', Economic Growth Center, Yale University;

Judith, B. and Dwyer, D., 1988, 'A Home Divided: Women and Income in the Third World', Stanford, California, Stanford University Press;

Judith, B. and Lloyd C., 1992, 'Beyond Female Headship: Family Research and Policy Issues for the 1990s', paper presented at the International Food Policy Research Institute-World Bank Conference on Intra-household Resource Allocation: Policy Issues and Research Methods, Washington, D. C.;

Kabeer, N., 1996, 'Agency, Well-being and Inequality: Reflections on the Gender Dimensions of Poverty', IDS Bulletin, 27:1, 11-21;

Kennedy, E., and Haddad, L., 1994, 'Are Pre-Schoolers from Female-Headed Households Less Malnourished? A Comparative Analysis of Results from Ghana and Kenya', Journal of Development Studies, 30(3):680-695.

Kennedy, E., and Peters P., 1992, 'Household food security and child nutrition: the interaction of income and gender of the household head', World Development, 20(8): 1077-85;

Kossoudji, S. and Mueller, E., 1983, 'The Economic Status of Female Headed Households in Rural Botswana', Economic Development and Cultural Changes, Vol. 31(3) pp; 831-859;

Kukanesen, R., 2003, 'Female Headed Households in BiH', United Nations in Bosnia and Herzegovina;

Lanjouw, P., Milanovic B, and Paternostro S, 1998, 'Poverty and the Economic, Transition How Do Changes in Economies of Scale Affect Poverty Rates for Different Households?' The World Bank Development Research Group Poverty and Human Resources;
Louat, F., Grosh, M. E and Gaag Van Der, J. ,1992, 'Welfare Implications of Female-headship in Jamaican Households', paper presented at the International Food Policy Research InstituteWorld Bank Conference on Intra-household Resource Allocation: Policy Issues and Research Methods, Washington, D. C;

Mickiewicz, T., 2005, Economic Transition in Central Europe and the Commonwealth of Independent States, Palgrave MacMillan, Haundmills and New York.

Milanovic, B., 1998, 'Income, inequality, and poverty during the transition from planned to market economy'. Washington, DC: World Bank

Moghadam, V. M., 1993, 'Modernizing women: Gender and social change in the Middle East. Boulder', CO: Lynne Rienner

Moghadam, V., 2005), 'The 'Feminization of Poverty' and Women's Human Rights'. SHS Papers in Women's Studies/ Gender Research No. 2. Gender Equality and Development Section UNESCO;

MUKHOPADHYAY, S., and GHATAK S., undated, 'Analysing Linkages Between Gender and Poverty: A Methodological Note';

National Statistical Institute Of Bulgaria, 2006, 'Comparative Tables by Census Years', available from http://www.nsi.bg/ Census_e/SrTables.htm, accessed on 3 August 2006;

Obarcanin, J., 2005, Report on the Present State and Future of Social Security in Bosnia and Herzegovina, Social Institutions Support Programme of Council of Europe;

Official Gazette RBIH, No. 2/92 'Law on Fundamental Rights of the Disabled Veterans and Families of the Killed Soldiers';

Owen, M, undated, 'Widows in Third World Nations', Encyclopedia of Death and Dying : vi-z, available from http://www. deathreference.com/Vi-Z/Widows-in-Third-World-Nations. html, accessed on 10 August 2006;

Paci, P. and Reilly, B., undated, 'Does Economic Liberalization Reduce Gender Inequality in the Labor Market: the Experience of the Transition Economies of Europe and Central Asia', draft, Poverty and Economic Management Division, Europe and Central Asia Region, The World Bank, Washington DC;

Paci, P., 2002, 'Gender in Transition', Human Development Unit, Eastern Europe and Central Asia Region, World Bank;

Quisumbing, A., haddad, L. and Pena, C., 1995, 'Gender and Poverty: New Evidence from 10 Developing Countries'. Food Consumption and Nutrition Division Discussion Paper No. 9, International Food Policy Research Institute, Washington, DC;

Ringen S, 2003, 'Population Crisis in Europe', Times Literary Supplement United Nations Population Fund: State of the World Population 2002, New York: UNFPA 2002 (www.unfpa. org) ISBN 0-89714-650-6, 80pp; 
Rogers, B. L., 1995, 'Alternative Definitions of Female Headship in the Dominican Republic', World Development, 23 (12), 2033-2039;

Rosenhouse, S., 1989, 'Identifying the Poor: Is 'Headship' a Useful Concept?’ World Bank Living Standard Measurement Study Working Paper No. 58;

Schnepf, S. V., 2004, 'The Feminisation of Poverty in Transition Countries: Evidence from Subjective Data', University of Hamburg University of Southampton;

State Agency For Statistics, Republika Srpska Institute OfStatistics, Federation Of BiH Instizute Of Statistics And World Bank, 2002, 'Welfare in Bosnia and Herzegovina, 2001: Measurement and Findings';

State Agency For Statistics, Republika Srpska Institute OfStatistics, Federation Of BiH Instizute Of Statistics And World Bank, 2002a, 'Bosnia-Herzegovina Living Standards Measurement Study Survey 2001- Basic Information Document'

State Agency For Statistics, Republika Srpska Institute Of Statistics, Federation Of BiH Institute Of Statistics And World Bank, 2002b, 'Bosnia-Herzegovina Living Standards Measurement Study Survey 2001- Abstract'

State Agency For Statistics For BiH, 2006, Notices; available from http://www.bhas.ba/Arhiva/2006/Saopcenja/Place/plate5_ 06.pdf\#search $=\% 22$ average $\% 20$ wages $\% 20$ in $\% 20$ RS\% 20 and $\% 2$ 0FBIH\%20\%22, accessed on 16 August 2006;

UNDP, 2002, 'Human Development Report: Bosnia and Herzegovina', United Nations. Development Programme Bosnia and Herzegovina;

United Nations Volunteers, 2004, 'Female Headed Households in post-war Srebrenica', available from http://unv.org/infobase/voices/2004/kosovo.htm, accessed on 28 August 2006;

Vaknin S, 2002, 'Women in Transition: From post-feminism to past femininity', Central European Review, available from http://www.cereview.org/01/2/vaknin2.html, accessed on 20 June 2006;

Vodopivec, M., 2002, 'Labour Market in the Post-War Bosnia and Herzegovina: How to Encourage Business to Create Jobs and Increase Worker Mobility'. Human Development Unit - South East Europe Country Unit Europe and Central Asia Region, The World Bank;

World Bank, 2003, Bosnia and Herzegovina: Poverty Assessment, Report No. 25343-BIH; 